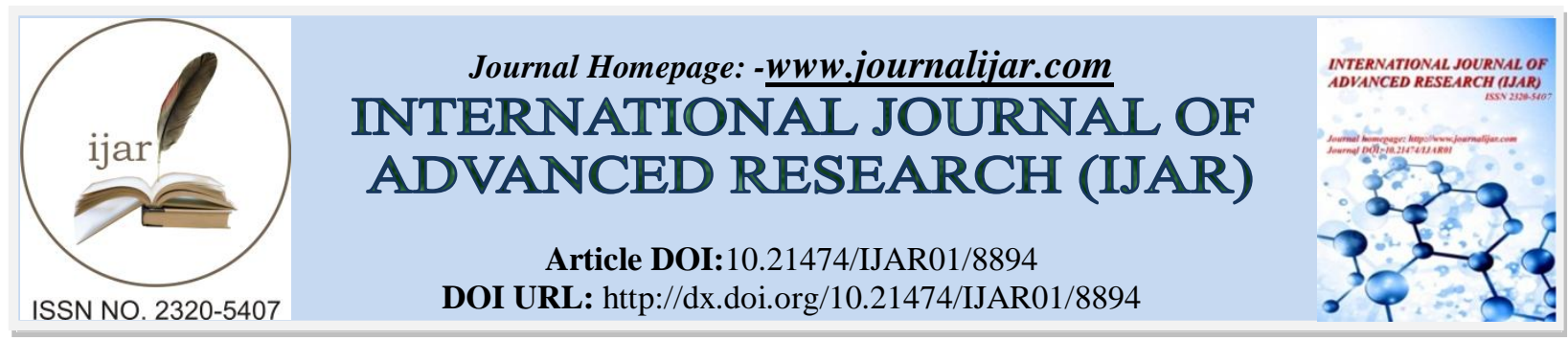

RESEARCH ARTICLE

\title{
COMPARISON OF POSTEROLATERAL AND LATERAL APPROACH FOR TOTAL HIP REPLACEMENT IN AVASCULAR NECROSIS OF FEMORAL HEAD: A RETROSPECTIVE STUDY OF 46 CASES.
}
Ahmad Zaki Barati ${ }^{1}$, Shi Lei ${ }^{1}$, Fan Xun Qi $^{1}$, Zhao Jun Peng ${ }^{2}$, Saraj U DDin Barati ${ }^{3}$ and Santosh Adhikari ${ }^{4}$.
1. Department of Orthopedics, First affiliated Hospital of Jiamusi University, Jiamusi, China.
2. Department of Human antomy and histoembryology. First affiliated Hospital of Jiamusi University, China.
3. Department of Orthopedics, Alkair Hospital, Kabul, Afghanistan.
4. Department of Pediatrics, First affiliated Hospital of Jiamusi University, Jiamusi, China.

\section{Manuscript Info}

Manuscript History

Received: 12 February 2019

Final Accepted: 14 March 2019

Published: April 2019

Key words:-

Total Hip Arthroplasty, Lateral approach, Posterolateral approach, Harris hip score.

\section{Abstract}

Aim: A retrospective study was conducted to compare the lateral approach and posterolateral approach in total hip arthroplasty in term of the Harris hip score, duration of surgery, length of incision and blood loss.

Methods: The study were done totally on 46 patients aged between 42 to 80 years. 23 patients were operated through the direct lateral hardinge approach while the other 23 patients were operated through the posterolateral approach. Those patients were operated in between years of 2012 to 2017 in the first Jiamusi university hospital. The data were collected from the medical records of the patients and direct contact with them. The collected data were analyzed with Spss 21.0 version software. The Chi-square test was used to make the comparison between the two groups.

Results: There was no significant difference in age, gender, duration of surgery, blood loss and size of incision. The p-value was greater than the $\alpha=0.05$. However, there was significantly difference in Harris hip score between both groups and the $\mathrm{p}$ value was 0,043 which is statistically significantly difference between the two groups.

Conclusion: In our study, patients treated with direct lateral approach had a better postoperative outcome with less complication than the patients treated with a standard posterolateral approach.

Copy Right, IJAR, 2019,. All rights reserved.

\section{Introduction:-}

Total hip arthroplasty is common and new established surgical treatment modality for the management of femoral neck fracture in elderly patients due to avascular necrosis, arthritic hip joint disease, high rate of non-united femur fracture, failure of internal fixation and osteoporotic bone disease while the most common indication for THA is osteoarthritis of the hip joint. Charnley initially used a transtrochanteric approach in total hip arthroplasty. Then the other different approaches have been introduced, such as the anterior (Smith Peterson), lateral (Hardinge), anterolateral (Watson Jones) and posterior (Gibson), which have been used for total hip replacement with good results.

Corresponding Author:-Shi Lei.

Address:-Department of Orthopedics, First affiliated Hospital of Jiamusi University, China. 
In 2010 about 33200 total hip joint arthroplasty were performed in the United States ${ }^{[27] .}$ By 2030 the demand for primary THR is estimated to grow by $174 \%$ to 572,000 procedures ${ }^{[28]}$. Direct lateral Hardinge approach for total hip arthroplasty has become one of the most successful surgical procedures in orthopedic surgery ${ }^{[34,35] .}$ There are many surgical approaches anterior, anterolateral, lateral, posterolateral, posterior and medial approach. The two most common surgical approaches are lateral and posterolateral approach Lateral approach has less muscle damage. Therefore, it has no hip joint dislocation and abductor muscle weakness and provides easy exposure of acetabular component and the proximal end of the femur and enabling an easy hip prosthesis insertion. Whereas in posterolateral approach there is damage to the external rotator muscles, as a result, it causes hip joint dislocation.

Many complications have been reported after total hip arthroplasty used lateral and posterolateral approaches. The most common postoperative complications after total hip arthroplasty are hip joint dislocation, sciatic nerve injury, superior gluteal nerve injury, abductor muscle weakness, and muscle injuries. Norwegian arthroplasty register (NAR) in 2011 reported that from 7,360 THA, the lateral approach was used in 53\% of the operations and the posterolateral approach in $28 \%$ of operations. Dislocation is the major problem after total hip arthroplasty and has a negative effect on the quality of life if it is recurrent (Enocson et al. 2009b). Pain in the presence of a degenerative hip joint as evidenced on imaging studies is the primary indication for surgery. The Patients who has no pain but has motion limitation, limp and leg length inequality are not the candidates for hip joint replacement surgery. In a study of a large inpatient database, Rasouli et al, found the higher risk of systemic complications with bilateral total hip replacement. Sepsis was reported by Stavrakis et al. Elderly patients with other comorbidities are not suitable candidates for such a procedure. Absolute contraindications include hip joint infection, obesity, severe dementia, severe osteoporosis, tobacco use, skin conditions such as psoriasis, and absence or relative insufficiency of the abductor musculature. The two groups were compared with respect to the duration of surgery, blood loss during surgery, incision size, and Harris hip score.

\section{Materials And Methods:-}

The study approval was granted by the Ethics Committee of the of Jiamusi university on (10-10-2017). A retrospective study was conducted on 46 patients who underwent total hip arthroplasy from 01-01-2012 to July 3107- 2017 treated by two different approaches. Both the conventional posterolateral and lateral approaches were performed by the experienced surgeon in first Jiamusi university hospital. Demographic data, postoperative length of incision, duration of surgery, blood loss and Harris hip scores (HHS) were collected from postoperative anesthesia note and from the postoperative note. The files of patients were requested for analysis in July 2016. Patients separated into two groups according to surgical approaches. 23 patients (14 males, 10 females; mean age 59.7 years; range from 42 to 79 years) were included in the group 1 in which hip joint capsules were exposed through lateral approach (Hardinge Approach), whereas 23 patients (10 males, 13 females; mean age 59.6 range 4378) were included in group 2 in which the hip joint was exposed through posterolateral approach. All the patients in lateral and conventional posterolateral approach were treated with cementless stem fixation and cup insertion. The related variables under our observation are the followings: Blood loss, length of incision and operation time, and Harris hip score. The indications for surgery were osteoarthritis, neck of femur fracture and avascular necrosis of femoral head. Regarding articulation, all patients' hips received metal on polyethylene articulation and were treated by cementless fixation. In both groups the lateral and posterolateral the patients were placed in lateral position. The length of the incision in the lateral group ranges from 8 to $18 \mathrm{~cm}$ and in posterolateral approach it ranges from 10 to $18 \mathrm{~cm}$. The amount of blood loss in lateral approach ranges from $200 \mathrm{ml}$ to $1500 \mathrm{ml}$ and in posterolateral approach it ranges from $100 \mathrm{ml}$ to $1000 \mathrm{ml}$. The duration of surgery in lateral group ranges from 1 hour and $20 \mathrm{minites}$ to 3 hours and 50minites while it ranges from 1 hour and 20mintes to 5hours and 30 minutes in posterolateral approach. For this study, we used, uncemented acetabular and femoral stem component. The prosthesis used was supplied by (United Orthopedics). The bearing surface was polyethylene- metal (cobalt chrome). All of the patients in our lateral and posterolateral approach received $28 \mathrm{~mm}$ and $32 \mathrm{~mm}$ femoral head size(United orthopedics instruments) Drainage was used in all the patients. All the patients received prophylactic antibiotics pre and postoperatively. Both AnteriorPosterior view (AP) and lateral view radiographs were taken to evaluate the anteversion and inclination angle. For the evaluation of cup placement, we used the Lewinnek criteria defining the range of inclination at $30^{\circ}-50^{\circ}$ and the range of anteversion at $5^{\circ}-25^{\circ}$ as the target range. The measurement of the varus and valgus stem orientation were done on the anterior radiograph defining a stem orientation of about $\pm 3^{\circ}$

Table 1:-Patient's demographic characteristics and procedure data

\begin{tabular}{|l|l|l|}
\hline Variables & Posterolateral approach & Lateral approach \\
\hline
\end{tabular}




\begin{tabular}{|l|l|l|}
\hline Age & $59(43-78)$ & $59(42-79)$ \\
\hline Gender(M/F) & $10 / 13$ & $13 / 10$ \\
\hline Operated hip(R/L) & $11 / 12$ & $14 / 9$ \\
\hline Diagnosis & Avascular necrosis & Avascular necrosis \\
\hline
\end{tabular}

\section{Statistics}

The collected data was entered in Microsoft excel spreadsheet, coded in number and then we analyzed data using SPSS version 21. Comparison of duration of surgery, length of incision and blood loss were done using Chi-Square with a significance level of 5\% $(\alpha=0.05)$, with 95 percent confidence interval and with the null hypothesis (H0) being regarded as no difference between them and the alternative hypothesis (H1) as there is the difference between them.

\section{Results:-}

Both groups (lateral and posterolateral approach) had 46 patients. There was no significant difference in age, gender, duration of surgery, blood loss and size of incision. However there was significant different in Harris hip score between both groups. The reason for the patients who underwent total hip arthropasty was Avascular necrosis of femoral head. The summary is given in the Table 2.

\section{Duration of surgery}

Duration of surgery were calculated in 46 patients in spss using chi square test to evaluated and the p-value was 0.409 which is greater than the $\alpha=0.05$. There was no significant difference between two groups in compare to the duration of surgery

Figure 1:-Measurement of the duration of surgery in lateral and posterolateral approach to the hip joint arthroplasty

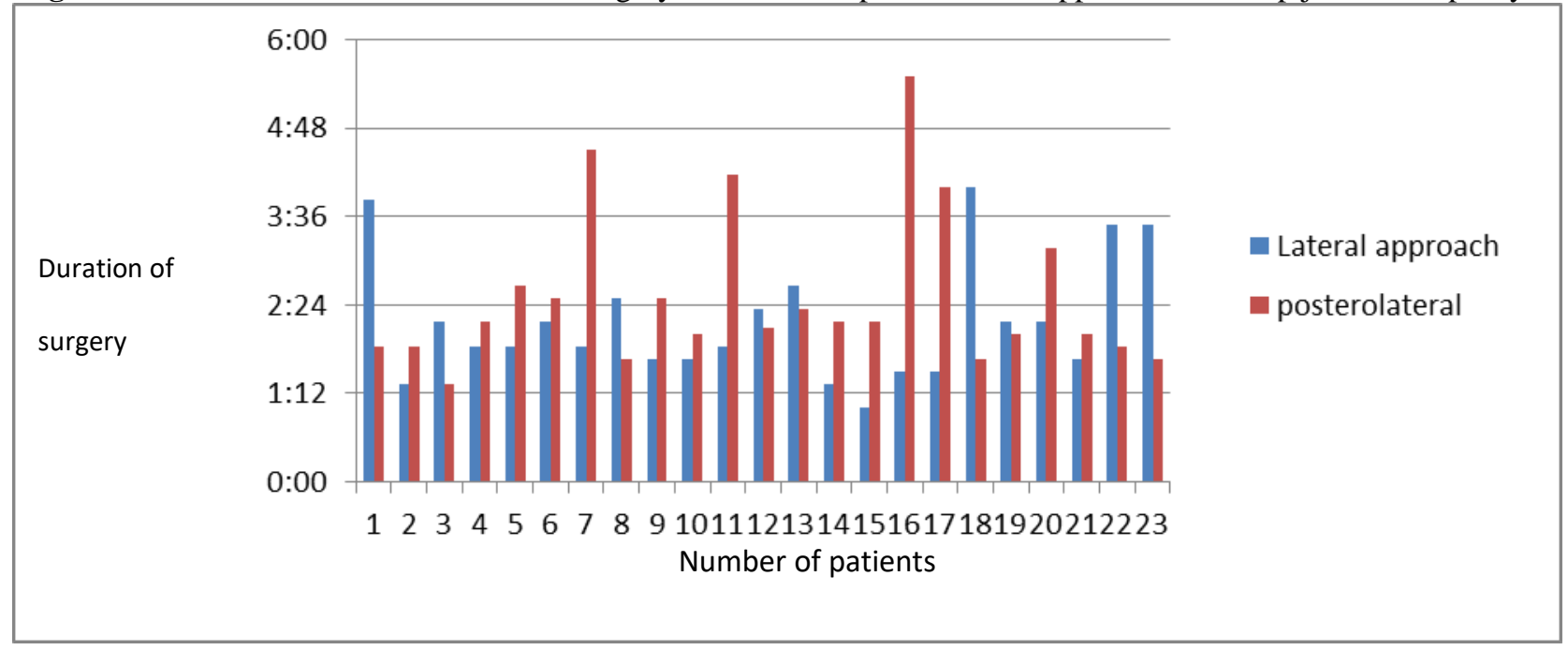

\section{Length of incision}

The lengths of incision were calculated in 46 patients in spss using chi square test to find out difference. P- value was 0.069 which is greater than the $\alpha=0.05$. The statistical analysis by Chi squared test showed no difference between two approaches for the number of cases studied.

\section{Blood loss}

There is no significant difference between with respect to blood loss between two groups. P-value is 0.597 which is greater than the $\alpha=0.05$. There was no statistically significant difference between two groups in compare to the blood loss. 
Figure 2:-Measurement of the amount of intraoperative blood loss in lateral and posterolateral approach to the hip joint arthroplasty.

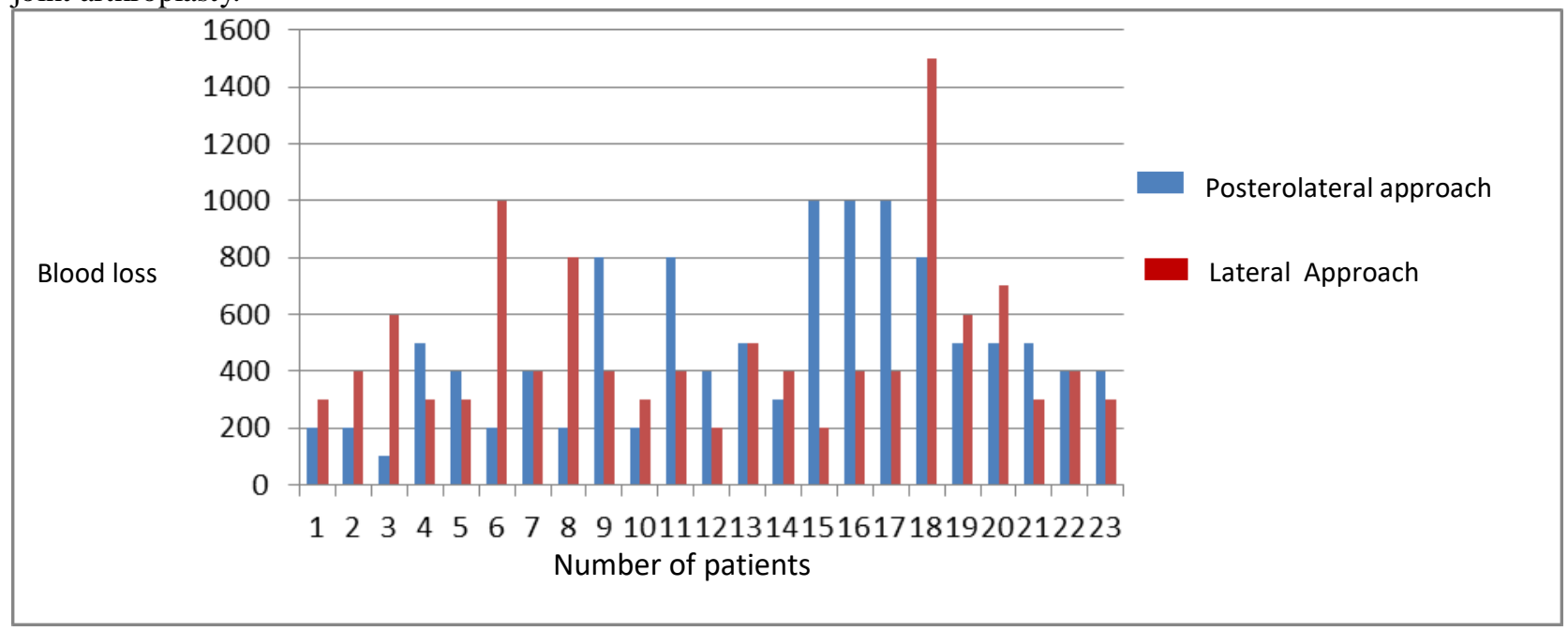

\section{Harris hip score}

Harris hip score was analyzed in 46 patients using chi square test, the p value was p-value was 0,039 which is less that $\alpha=0.05$. The statistical analysis by Chi squared test showed that there is statistically significant difference regarding Harris hip score between two groups in number of cases studied.

Table 2:-Comparison between the LA and PLA Intraoperative Variables. PL: Posterolateral approach LA: Lateral approach HHS: Harris hip score

\begin{tabular}{|l|l|l|l|l|}
\hline Variable & Operation type & PL & \multicolumn{2}{l|}{ PA-value } \\
\hline \hline Bleeding $(\mathrm{mL})$ & THA & $491 \pm 279$ & $482 \pm 293$ & 0.597 \\
\hline Incision size(cm) & THA & $13 \pm 2.497$ & $12 \pm 3.059$ & 0.069 \\
\hline Durationof surgery(hour:minites) & THA & $2: 30 \pm 1: 03$ & $2: 10 \pm 0: 49$ & 0.409 \\
\hline HHS & THA & $98 \pm 4.262$ & $96 \pm 5.413$ & 0.039 \\
\hline
\end{tabular}

\section{Complications:}

There was one case of hip joint dislocation in posterolateral approach whereas there was no dislocation in lateral approach.

\section{Discussion:-}

In our study that we conducted in the first affiliated hospital of Jiamusi university in patients who undergone total hip arthroplasty through both lateral approach and posterolateral approach. We found out that posterolateral approach was associated with the risk of hip joint dislocation postoperatively which can be non-satisfactory for the patient in compare the direct lateral(transgluteal ) approach. There is higher risk of dislocation in posteriorlateral approach(Arthursson et al. 2007, Lindgren et al. 2012 ) ${ }^{[33]}$.Posterior hip joint structure stability is important which can be affected by damage to the external rotators muscle as a result hip joint dislocation occurs. We had no hip joint dislocation in direct lateral approach, however there was one hip joint dislocation postoperatively in posterolateral approach. Mostly the dislocation of the hip join occurs within the first six months after the surgery done through the posterolateral approach ${ }^{[45]}$. Ko et $\mathrm{al}^{[46]}$ recommended that when using the posterolateral approach we must repair the hip joint capsule and the external rotator muscles should be reinserted, since they did not find hip joint dislocation postoperatively with this repair and when posterior repair was not performed the rate of dislocation was $1.9 \%$ postoperatively.In a study by Varley and Parker at el there were high rate of dislocation with posterior 
approach $(5.1 \%)$, compared to anterior approach to the hip joint postoperatively ${ }^{[52]}$. In a study by Unwin and Thomas at el shown a high rate of dislocation (2.4\%) with posterior approach when compared to the lateral transgluteal approach ${ }^{[53]}$ In comparative study by Bush et al, the hip joint dislocations were higher in number in posterior group $(4.5 \%)$ than the anterior approach ${ }^{[49]}$.Several studies have reported higher rate of dislocations with posterior approach than the transgluteal approach to the hip joint ${ }^{[54,55]}$.Some of the studies reported that mental dysfunction can be a risk factor for hip joint dislocation in elderly patients ${ }^{[12]}$. The hip joint dislocation is associated with the femoral head size, the use of large femoral head size decrease the chance of hip joint dislocation (Amlie et al. 2010, Bistolfi et al. 2011, Ho et al. 2012 ${ }^{[37,38,39]}$.In our study the patients demographic characteristics were relatively similar in both surgical approaches. Furthermore there was no difference in duration of surgery, size of incision and blood loss comparatively between two groups, however there was significant difference in Harris hip score postoperatively between two groups, the p-value was 0,039 . In the study by Chinundorn Putananon at el in which they compared the Harris hip score between anterior, lateral and posterior approaches they found out that Anterior and Lateral approach were ranked first and second, they also recommended lateral approach as first surgical approach with lower risk of pain, function and complications which supports our research ${ }^{[31]}$. In the study of short term outcome postoperatively conducted by L Stephan at el there was no significant difference in Harris hip score between two groups ${ }^{[32]}$. Keene and Parker et al ${ }^{[48]}$ reported in a comparison between anterolateral and posterior approach for total hip replacement surgery, they found that the anterolateral approach was associated with increase blood loss, duration of surgery and infection whereas the posterior group was associated with the high dislocation rate and more thromboembolic complication.

\section{Conclusion:-}

In our retrospective study that we performed, our results showed that the patients operated through the direct lateral approach were safe and had no complications postoperatively in compare to the standard posterolateral approach in experienced hand surgeon. Furthermore direct lateral approach THA provided, better postoperative HHS, and had no hip joint dislocation thus achieved satisfactory clinical and radiological results. Although there was no statistically significant difference between two in duration of the operation, the lateral approach was associated with the short duration of operation.

\section{References:-}

1. Baba T, Homma Y, Takazawa N, Kobayashi H, Matsumoto M, Aritomi K, et al. Is urinary incontinence the hidden secret complications after total hip arthroplasty? Eur J Orthop Surg Traumatol. 2014; 24(8):1455-60. 40.

2. Tamaki T, Oinuma K, Shiratsuchi H, Akita K, Iida S. Hip dysfunction-related urinary incontinence: a prospective analysis of 189 female patients undergoing total hip arthroplasty. Int J Urol. 2014; 21(7):729-31.

3. Hardinge K. The direct lateral approach to the hip. J Bone Joint Surg Br 1982; 64:17-9.

4. This approach provides adequate exposure of both the proximal femur and acetabulum.12 Hoppenfeld S, DeBoer P, Buckley R. Surgical exposures in orthopaedics: the anatomic approach. Philidelphia, PA: Lippincott Williams and Wilkins; 2009.

5. Masonis JL, Bourne R. Surgical approach, abductor function, and total hip arthroplasty dislocation. Clin Orthop Relat Res 2002;405:46-53.

6. Hoppenfeld S, De Boer P. The hip. In: Surgical exposures in orthopaedics. Philadelphia: LippincottHaven; 1984. p.301-56.

7. Afonso MAR, Franco JS, Cabral FJP, D’Angelo MD, Alves FRV. 2008

8. Svenson O, Sköld S, Blomgen G. Integrity of the gluteus medium after the transgluteal approach in total hip arthroplasty. J Arthroplasty. 1990; 5:57-60.

9. Ritter MA, Harty LD, Keating ME, Faris PM, Meding JB. A clinical comparison of the anterolateral and posterolateral approaches to the hip. Clin Orthop Relat Res. 2001; 385:95-99.

10. Amlie E, Havelin LI, Furnes O, Baste V, Nordsletten L, Hovik O, et al. Worse patient-reported outcome after lateral approach than after anterior and posterolateral approach in primary hip arthroplasty. A cross-sectional questionnaire

11. Rami Madanat \& Tatu J. Mäkinen \& Mikko T. Ovaska \& Martti Soiva \& Tero Vahlberg \& Jussi Haapala

12. Enocson A, Tidermark J, Törnkvist H, Lapidus LJ (2008) Dislocation of hemiarthroplasty after femoral neck fracture: better outcome after the anterolateral approach in a prospective cohort study on 739 consecutive hips. Acta Orthop 79:211-217

13. Pajarinen J, Savolainen V, Tulikoura I, Lindahl J, Hirvensalo E (2003) Factors predisposing to dislocation of the Thompson hemiarthroplasty. Acta Orthop 74:45-48 
14. Keene GS, Parker MJ (1993) Hemiarthroplasty of the hip - the anterior or posterior approach? A comparison of surgical approaches. Injury 24:611-613

15. Bush JB, Wilson MR (2007) Dislocation after hip hemiarthroplasty: anterior versus posterior capsular approach. Orthopedics 30:138-144

16. Suh KT, Park BG, Choi YJ (2004) A posterior approach to primary hip arthroplasty with soft tissue repair. Clin Orthop 418:162-167

17. Ko CK, Law SW, Chiu KH (2001) Enhanced soft tissue repair using locking loop stich after posterior approach for hip hemiarthroplasty. J Arthroplasty 16:207-211

18. Ramesh M, O’Byrne JM, McCarthy N, Jarvis A, Mahalingham K, Cashman WF (1996) Damage to the superior glutal nerve after the Hardinge approach to the hip. J Bone Joint Surg Br 78:903-906

19. Anders Enocson \& Carl Johan Hedbeck \& Hans Törnkvist \& Jan Tidermark \& Lasse J. Lapidus

20. Woo RY, Morrey BF (1982) Dislocations after total hip arthroplasty. J Bone Jt Surg Am 64:1295-1306

21. Biedermann R, Tonin A, Krismer M, Rachbauer F, Eibl G, Stockl B (2005) Reducing the risk of dislocation after total hip arthroplasty: the effect of orientation of the acetabular component. J Bone Jt Surg Br 87:762-769

22. Lewinnek GE, Lewis JL, Tarr R, Compere CL, Zimmerman JR (1978) Dislocations after total hip-replacement arthroplasties. J Bone Jt Surg Am 60:217-220

23. Dorr LD, Wan Z (1998) Causes of and treatment protocol for instability of total hip replacement. Clin Orthop Relat Res 144- 151

24. Adrian e. Weale, piers newman, ian t. Ferguson, gordon c. Bannister

25. Margot van der Grinten*†, Max Reijman $\dagger$, Frans $\mathrm{C}$ van Biezen $\dagger$ and Jan AN Verhaar $\dagger$

26. Kurtz, S, Ong, K, Lau, E, Mowat, F, Halpern M. Projections of primary and revision hip and knee arthroplasty in the United States from 2005 to 2030. J Bone Joint Surg Am. 2007;89(4):780785

27. CentersforDiseaseControlandPrevention.2013.Nationalhospitaldischarge survey: 2010 table, procedures by selected patient characteristics. Centers for Disease Control and Prevention, Atlanta, GA.

28. Kurtz S, Ong K, Lau E, Mowat F, Halpern M. 2007. Projections of primaryandrevisionhipandkneearthroplastyintheUnitedStatesfrom 2005 to 2030. J. Bone Joint Surg. Am. 89:780-785.

29. Einar Amlie, Leif I Havelin, Ove Furnes, Valborg Baste, Lars Nordsletten, Oystein Hovik \& Sigbjorn Dimmen. Worse patient-reported outcome after lateral approach than after anterior and posterolateral approach in primary hip arthroplasty. Acta Orthopaedica 2014; 85 (5): 463-469

30. Nils P Hailer1, Rüdiger J Weiss2, André Stark3, and Johan Kärrholm4. The risk of revision due to dislocation after total hip arthroplasty depends on surgical approach, femoral head size, sex, and primary diagnosis. Acta Orthopaedica 2012; 83 (5): 442

31. Chinundorn PutananonHarit TuchindaAlisara ArirachakaranSiwadol WongsakThana NarinsorasakJatupon Kongtharvonskul. Comparison of direct anterior, lateral, posterior and posterior-2 approaches in total hip arthroplasty: network meta-analysis.Europian journal of orthopedics and traumatology ,2018

32. W-C Witzle, L Stephan, F Krummenauer, A Neuke and K-P Günther. Short-term outcome after posterior versus lateral surgical approach for total hip arthroplasty - a randomized clinical trial. European Journal of Medical Research2009

33. Arthursson AJ, Furnes O, Espehaug B, Havelin LI, Soreide JA. Prosthesis survival after total hip arthroplastydoes surgical approach matter? Analysis of 19,304 Charnley and 6,002 Exeter primary total hip arthroplasties reported to the Norwegian Arthroplasty Register . Acta Orthop. 2007

34. McFarland B, Osborne G. Approach to the hip: a suggested improvement on Kocher's method. J Bone Joint Surg Br 1954;36B:364-7.

35. Hardinge K. The direct lateral approach to the hip. J Bone Joint Surg Br 1982; 64B:179.

36. Hardinge approach to all primary hip arthroplasty which, according to the Norwegian Arthroplasty Register, is the standard approach to hip operations done in Norway. Primary total hip arthroplasty: a comparison of the lateral Hardinge approach to an anterior mini-invasive approach. orthopedic Reviews 2009; volume 1:e27

37. Amlie E, Hovik O, Reikeras O. Dislocation after total hip arthroplasty with 28 and 32-mm femoral head. J Orthop Traumatol 2010; 11 (2): 111-5.

38. Bistolfi A, Crova M, Rosso F, Titolo P, Ventura S, Massazza G. Dislocation rate after hip arthroplasty within the first postoperative year: $36 \mathrm{~mm}$ versus $28 \mathrm{~mm}$ femoral heads. Hip Int 2011; 21 (5): 559-64.

39. Ho K W, Whitwell G S, Young S K. Reducing the rate of early primary hip dislocation by combining a change in surgical technique and an increase in femoral head diameter to $36 \mathrm{~mm}$. Arch Orthop Trauma Surg $2012 ; 132$ (7): 1031-6. 
40. Jakob van Oldenrijk1, Piet V J M Hoogland2, Gabriëlle J M Tuijthof1, Ruby Corveleijn3, Tom W H Noordenbos2, and Matthias U Schafroth1. Soft tissue damage after minimally invasive THAA comparison of 5 approaches. Acta Orthopaedica 2010; 81 (6): 696-702

41. Suh K T, Park B G, Choi Y J. A posterior approach to primary total hip arthroplasty with soft tissue repair. Clin Orthop 2004; (418): 162-7.

42. Lavigne P, Loriot de Rouvray T H. The superior gluteal nerve. Anatomical study of its extrapelvic portion and surgical resolution by trans-gluteal approach. Rev Chir Orthop Reparatrice Appar Mot 1994; 80: 188-95.

43. Anders Enocson1, Carl-Johan Hedbeck1, Jan Tidermark1,3, Hans Pettersson2, Sari Ponzer1, and Lasse J Lapidus1.A prospective cohort study of 713 consecutive hips. Acta Orthopaedica 2009; 80 (2): 184-189

44. Nathan Wayne,1Reinhard Stoewe2 1Sykehuset Buskerud Vestre Viken, Drammen.Comparison between lateral approach to an anterior minimal invasive approach.Orthopedics reviews 2009

45. Paton RW, Hirst P. Hemiarthroplasty of the hip and dislocation. Injury. 30. 1989;20(3):167-9.

46. Ko CK, Law SW, Chiu KH. Enhanced soft tissue repair using locking loop 35. stitch after posterior approach for hip hemiarthroplasty. J Arthroplasty. 2001; 16(2):207-11

47. Masjudin Tumin, Kyung Soon Park, Azlina Amir Abbas and Taek Rim Yoon. Comparison of the Outcome in Bilateral Staged Total Hip Arthroplasty: Modified Two-Incision Minimally Invasive Technique versus the Conventional Posterolateral Approach

48. Bernd Fink*, Alexander Mittelstaedt, Martin S Schulz, Pavol Sebena, Joachim Singer. Comparison of a minimally invasive posterior approach and the standard posterior approach for total hip arthroplasty A prospective and comparative study. Journal of Orthopaedic Surgery and Research 2010, 5:46

49. Bush JB, Wilson MR. Dislocation after hip hemiarthroplasty: anterior versus posterior capsular approach. Orthopedics 2007; 30: 138-144

50. Jolles BM, Bogoch ER. Posterior versus lateral surgical approach for total hip arthroplasty in adults with osteoarthritis. Cochrane Database Syst Rev 2006; 19: CD003828

51. Hardinge K. The direct lateral approach to the hip. J Bone Joint Surg Br 1982; 64: 17-19.

52. Varley J, Parker MJ. Stability of hip hemiarthroplasties. Int Orthop 2004; 28: 274-277.

53. Unwin AJ, Thomas M. Dislocation after hemiarthroplasty of the hip: a comparison of the dislocation rate after posterior and lateral approaches to the hip. Ann R Coll Surg Engl 1994; 76: 327-329.

54. Rogmark C, Fenstad AM, Leonardsson O, Engesæter LB, Kärrholm J, Furnes O, Garellick G, Gjertsen JE. Posterior approach and uncemented stems increases the risk of reoperation after hemiarthroplasties in elderly hip fracture patients. Acta Orthop 2014; 85: 1825.

55. Keene GS, Parker MJ. Hemiarthroplasty of the hip-the anterior or posterior approach? A comparison of surgical approaches. Injury 1993; 24: 611-613.

56. Adrian e. Weale, piers newman, ian t. Ferguson, gordon c. Bannister. Nerve injury after posterior and direct lateral approaches for hip replacement. J bone joint surg [br] 1996;78-b:899-902

57. Richard S.Snell, MD, PHD.Clinical anatomy by regions. $8^{\text {th }}$ edition 2007 United State Of America

58. tephen Kishner, MD, MHA Professor of Clinical Medicine, Physical Medicine and Rehabilitation Residency Program Director, Louisiana State University School of Medicine in New Orleans.Hip joint anatomy . Medscape Dec 07, 2017

59. GS Kulkarni MS MS (Ortho) FRCS FICS Director, Professor and Head Postgraduate Institute of Swasthiyog Pratishthan Miraj, Maharashtra.volume 4.Textbook of Orthopedics and Trauma. Ajanta Press 2008

60. Kim Bengochea, Regis University, Denver.Anatomy of the hip joint. Kenhub(2018). 